\title{
Distribution of pore water pressure in an earthen dam considering unsaturated-saturated seepage analysis
}

\author{
Kumar Venkatesh ${ }^{1 a}$, Siva Ram Karumanchi ${ }^{2}$ \\ ${ }^{1}$ Assistant Professor, Civil Engineering Department, MNNIT, Allahabad, India \\ ${ }^{2}$ M. Tech Scholar, Civil Engineering Department, MNNIT, Allahabad, India
}

\begin{abstract}
The variation of pore water pressure in earthen dams plays an important role in maintaining its stability. The pore water pressure within the dam are altered by the external loading conditions like rapid drawdown of reservoir water, earthquake loading and raise of water table caused by infiltration of rainfall. The seepage through an earthen dam involves saturated and unsaturated flows but to avoid complexity in solving the non-linear partial differential equations, the flow in unsaturated zone is neglected and seepage analysis is carried by constructing the flow net in which the pore water pressures beyond the free surface is taken as zero. In actual conditions negative pore water pressure develops beyond the free surface due to the capillarity which leads development to the matrix suction of the soil. In this paper a comparative study on distribution of pore pressure in a zoned earthen dam under steady state and transient conditions had been carried out considering unsaturated-saturated seepage theory. To solve the non-linear partial differential equations, finite element method has been adopted in the present study. The earthen dam has been modeled in different stages. At each stage a new parameter was added and parametric analysis was carried out. The results indicate that negative pore water pressure developed at the downstream side and the pore pressures at the mid-levels of the core are high. This specifies that, soils with low permeability have higher pore pressure. The pore pressures appeared to be higher in upstream side during rapid drawdown compared to steady state.
\end{abstract}

\section{Introduction}

The seepage analysis is mainly in the interest of slope stability of the earth retaining structures, hydraulic structures etc. from geotechnical point of view. But in general there are seepage related problems that may be ignored like piping failure in earthen dams, capillary siphoning, infiltration of rainfall etc. These factors are of certain interest for the detailed stability analysis of an earthen dam and its maintenance.

Since Casagrande's (1937) classic paper "Seepage through dams," seepage problems in geotechnical engineering have been generally solved by sketching flow nets. This method was based on the assumption that water flows only in the saturated zone. This method of solution is practical for simple steady state problems where the boundary of the flow region is clearly defined and the soil conditions are not too complex. However, many seepage problems of practical interest are complex, and a flow-net solution is not feasible [1].

Over the years, the calculation of seepage had been simplified with application of numerical methods like finite element method, finite difference method etc. The first step in the determination of automatic flow net by finite element method was given by Fred T. Tracy and N. Radhakrishnan, (1989). They used Cauchy-Riemann equations to determine the correct boundary conditions.
In saturated condition the phreatic line was assumed to be upper boundary for confined flow conditions [1].

The results obtained from these assumptions are approximate and analysis was also done based on several assumptions ignoring some criteria. To overcome these defects, a unsaturated condition was also include in determintaion of seepage where the upper boundary varies with the degree of saturation which inturn depends on the capillarity of the soil. In the capillary zone the pore water pressures are taken as negative with respect to the atmosperic pressure and the present magnitude of matrix suction have found to be crucial in determining the properties of the unsaturated soils which are required for the seepage analysis [2]. The behavior of flow through soil in the analysis of saturated-unsaturated condition is based on the soil-water charateristic curve (SWCC) which is defined as the relation between degree of saturation and matrix suction [4]. The matrix suction is usually obtained by drying or wetting of a soil sample under a constant stress while monitoring the water released from or absorbed by the specimen and the total volume change of the specimen (centrifuge method).

\footnotetext{
$\overline{{ }^{a}}$ Kumar Venkatesh: venkatesh@mnnit.ac.in
} 


\section{Formulation}

\subsection{Steady state analysis}

The steady state seepage analysis depends only on the permeability of soil materials. In steady-state conditions, equation for laminar, two-dimensional flow in homogeneous, isotropic, porous media was developed by Terzaghi (1943) by using Laplace equation, rigorous developments can be found in Bear (1972), Cedergren (1977), and Harr (1962).

The governing differential equation for 3-dimensional seepage analysis is

$$
\frac{\partial}{\partial x}\left(k_{x} \frac{\partial h}{\partial x}\right)+\frac{\partial}{\partial y}\left(k_{y} \frac{\partial h}{\partial y}\right)+\frac{\partial}{\partial z}\left(k_{z} \frac{\partial h}{\partial z}\right)=0
$$

Where,

$\mathrm{h}=$ head in $\mathrm{m}$

$k_{x}, k_{y}, k_{z}=$ permeability in $\mathrm{x}, \mathrm{y}, \mathrm{z}$ directions

\subsection{Transient seepage analysis}

The transient state condition is a variable of time and degree of saturation of the soil. So an initial condition needs to be described aside from boundary conditions. In this paper, the standard H-based Richards's equation is used to determine the seepage and is expressed as follows

$\frac{\partial}{\partial x}\left(k_{x} \frac{\partial h}{\partial x}\right)+\frac{\partial}{\partial y}\left(k_{y} \frac{\partial h}{\partial y}\right)+\frac{\partial}{\partial z}\left(k_{z}\left(\frac{\partial h}{\partial z}\right)\right)=\gamma_{w} m_{w}^{2} \frac{\partial h}{\partial t}$

Where $\gamma_{w}, m_{w}^{2}$ are unit weight of water, coefficient of water storage constant with the slope of SWCC. Figure 1 show suction vs volumetric water content for different soil.

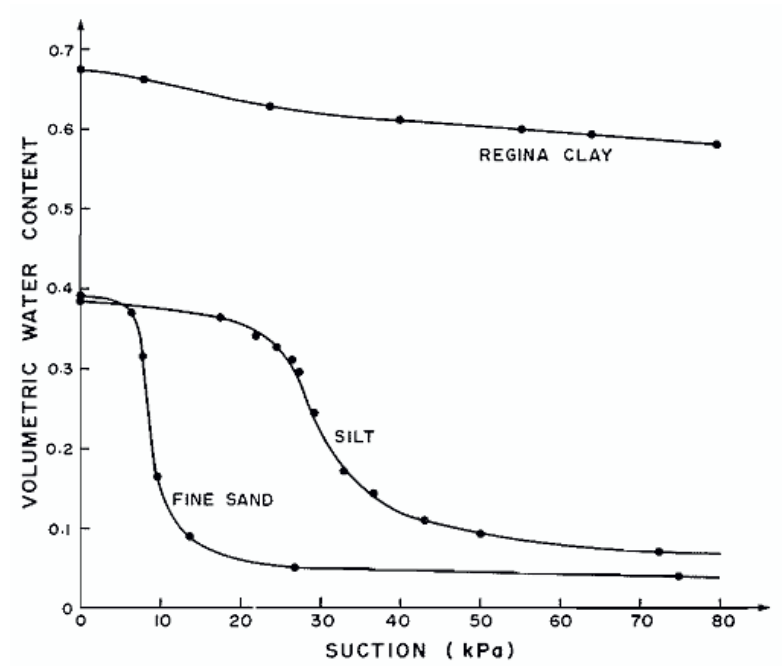

Figure1. SWCC for fine sand, silt and regina clay

\section{Numerical modelling}

The analysis of flow through an earthen dam by conventional and analytical methods is tedious and the main complexity is involved in transient flow conditions, interaction between sheet pile and soil. Though, finite element analysis is efficient in analyzing the flow through an earthen dam.

In this paper, the numerical model of an earthen dam was developed and parametric study on pore water pressure distribution in the earthen dam was studied for different condition. Three dimensional 4 noded tetrahedron elements were used for the finite element modeling.

\subsection{Geometry of the model}

The selection of geometry of an earthen dam is based on various literature review and suitable recommendations as shown in Figure 2. 3D meshing of earthen dam with sheet pile and horizontal drains are shown in Fgure 3. The height of dam is fixed to $30 \mathrm{~m}$. The inclination of upstream and downstream slopes is 3 (horizontal): 1 (vertical) and 2.5 (horizontal):1 (vertical). The top width is restricted to $10 \mathrm{~m}$ length and base width is $175 \mathrm{~m}$ in length. The thickness of the dam is taken as $50 \mathrm{~m}$. In the case of pervious foundations, the depth of foundation is taken as $40 \mathrm{~m}$. Table 1 represents the different soil properties used in components of earthen dam where as Table 2 shows the interface properties between soil and sheet pile.

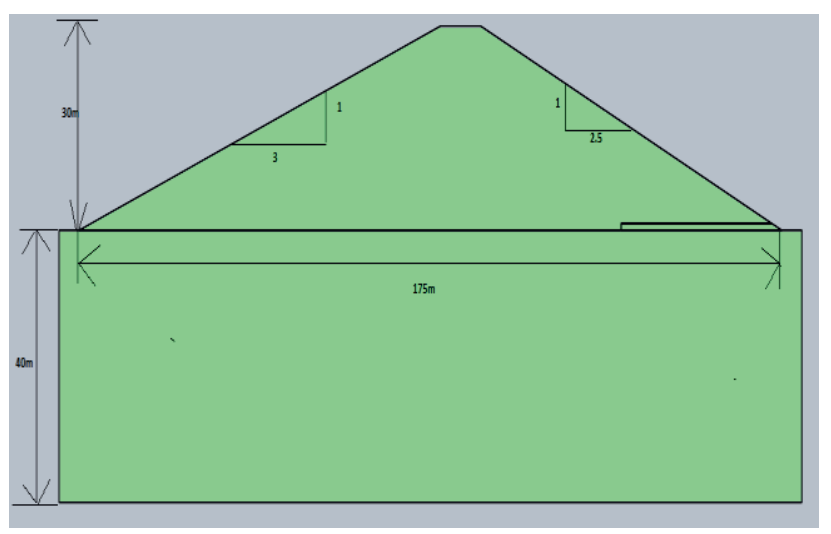

Figure 2. Geometry of a homogeneous earthen dam with blanket drain 


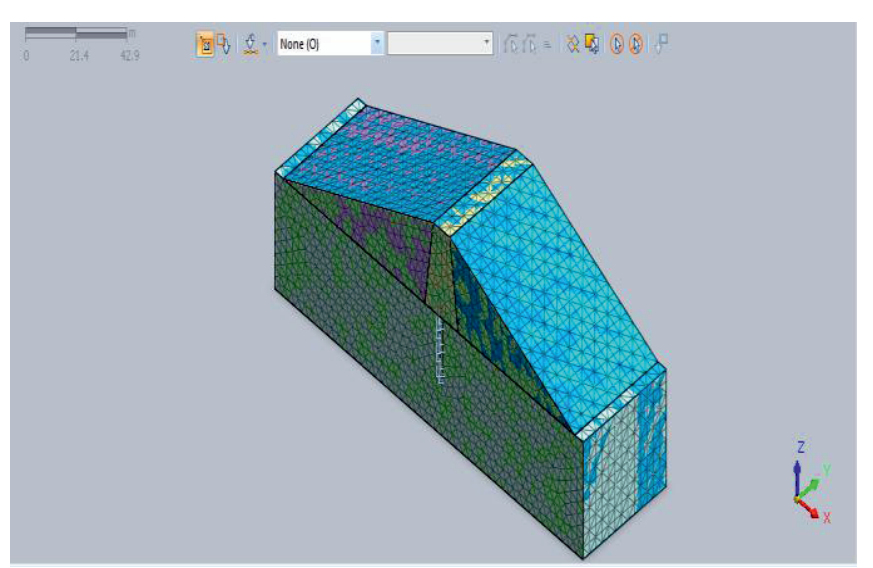

Figure 3. 3D meshing of a zoned earth dam with sheet pile and horizontal drain

Table 1. The properties of different types of soils used in components of earthen dam

\begin{tabular}{|l|l|l|l|l|l|l|l|}
\hline $\begin{array}{l}\text { Component } \\
\text { s of earthen } \\
\text { dam }\end{array}$ & $\mathrm{E}$ & $\gamma$ & $\gamma_{\text {sat }}$ & $\mathrm{e}_{0}$ & $\mathrm{~K}_{\mathrm{x}, \mathrm{y}, \mathrm{z}}$ & $\mathrm{C}$ & $\varphi$ \\
\hline Core & 40000 & 21 & 22 & $\begin{array}{l}0 . \\
5\end{array}$ & $\begin{array}{l}1.00 \mathrm{E} \\
-08\end{array}$ & $\begin{array}{l}3 \\
0\end{array}$ & $\begin{array}{l}35 . \\
6\end{array}$ \\
\hline Filter & 50000 & 20 & 23 & $\begin{array}{l}0 . \\
5\end{array}$ & $\begin{array}{l}0.000 \\
1\end{array}$ & 0 & 33 \\
\hline Dam shell & 52000 & 17 & 22 & $\begin{array}{l}0 . \\
5\end{array}$ & $\begin{array}{l}1.00 \mathrm{E} \\
-06\end{array}$ & 0 & 33 \\
\hline Drain & 50000 & 19 & 21 & $\begin{array}{l}0 . \\
5\end{array}$ & $\begin{array}{l}2.78 \mathrm{E} \\
-06\end{array}$ & 0 & 39 \\
\hline Foundation & $2.00 \mathrm{E}+0$ & 23 & 26 & $\begin{array}{l}0 . \\
5\end{array}$ & $\begin{array}{l}1.00 \mathrm{E} \\
-08\end{array}$ & 5 & 39 \\
& 6 & & & & \\
\hline
\end{tabular}

\section{Where,}

$\mathrm{E}=$ Elastic modulus, $\mathrm{kN} / \mathrm{m}^{2}$

$\gamma=$ Unit weight of soil, $\mathrm{kN} / \mathrm{m}^{3}$

$\gamma_{\text {sat }}=$ Saturated unit weight of soil, $\mathrm{kN} / \mathrm{m}^{3}$

$\mathrm{e}_{0}=$ Initial void ratio

$\mathrm{K}_{\mathrm{x}, \mathrm{y}, \mathrm{z}}=$ Coefficient of permeability, $\mathrm{m} / \mathrm{sec}$

$\mathrm{C}=$ Cohesion, $\mathrm{kN} / \mathrm{m}^{2}$

$\varphi=$ Angle of internal friction in degree

Table 2. The interface properties between soil and sheet pile

\begin{tabular}{|l|l|l|l|l|}
\hline Name & $\begin{array}{l}\mathrm{K}_{\mathrm{n}} \\
\left(\mathrm{kN} / \mathrm{m}^{3}\right)\end{array}$ & $\begin{array}{l}\mathrm{K}_{\mathrm{t}} \\
\left(\mathrm{kN} / \mathrm{m}^{3}\right)\end{array}$ & $\begin{array}{l}\mathrm{C} \\
\left(\mathrm{kN} / \mathrm{m}^{2}\right)\end{array}$ & $\varphi$ \\
\hline $\begin{array}{l}\text { Interface } \\
\text { Material } \\
\text { (Wizard) }\end{array}$ & $5.50 \mathrm{E}+07$ & $5.00 \mathrm{E}+06$ & 26 & $36^{0}$ \\
\hline
\end{tabular}

where,

$\mathrm{K}_{\mathrm{n}}=$ Coefficient of rigidity (normal elastic constant)

$\mathrm{K}_{\mathrm{t}}=$ Coefficient of rigidity (tangential elastic constant)
The boundary condition for steady state seepage is as follows:

a. Constant head of $26 \mathrm{~m}$ at upstream slope,

b. Constant head at downstream slope has been kept as zero seepage line and flow.

c. Discharge below the base is zero for confined follows

The boundary condition for transient seepage is as

a. The upstream slope is subjected to varying water level with respect to time.

b. Drawdown rate of $2 \mathrm{~m} /$ day has been considered in the present study, which is shown in Table 3.

Table 3 Drawdown rate with respect to time for five days

\begin{tabular}{|c|c|}
\hline $\begin{array}{c}\text { Time } \\
(\text { Hrs. })\end{array}$ & $\begin{array}{c}\text { Water level } \\
(2 \mathrm{~m} / \text { day }) \\
(\mathrm{m})\end{array}$ \\
\hline 24 & 24 \\
\hline 48 & 22 \\
\hline 72 & 20 \\
\hline 96 & 18 \\
\hline 120 & 16 \\
\hline
\end{tabular}

\section{Results and Discussion}

\subsection{Effect of horizontal drain on pore water pressure}

It has been observed from Figure 4 that increase in length of the drain reduces the pore water pressure (PWP in $\mathrm{kN} / \mathrm{m}^{2}$ ) at the downstream side of the dam. But at the upstream side, the pore water change is negligible and it coincides with the values of pore water pressure of earth dam without drain. Figure 5 shows the contours of pore water pressure with horizontal drain.

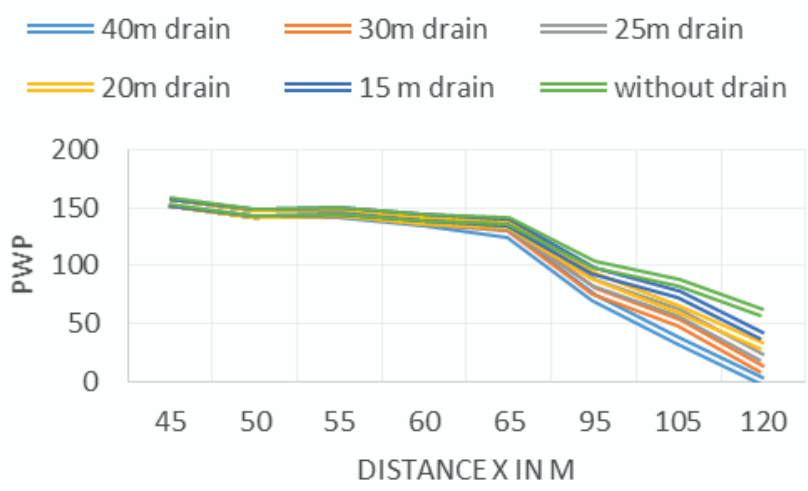

Figure 4. Pore water pressure $\left(\mathrm{kN} / \mathrm{m}^{2}\right)$ variation in earthen dam with different drain length 


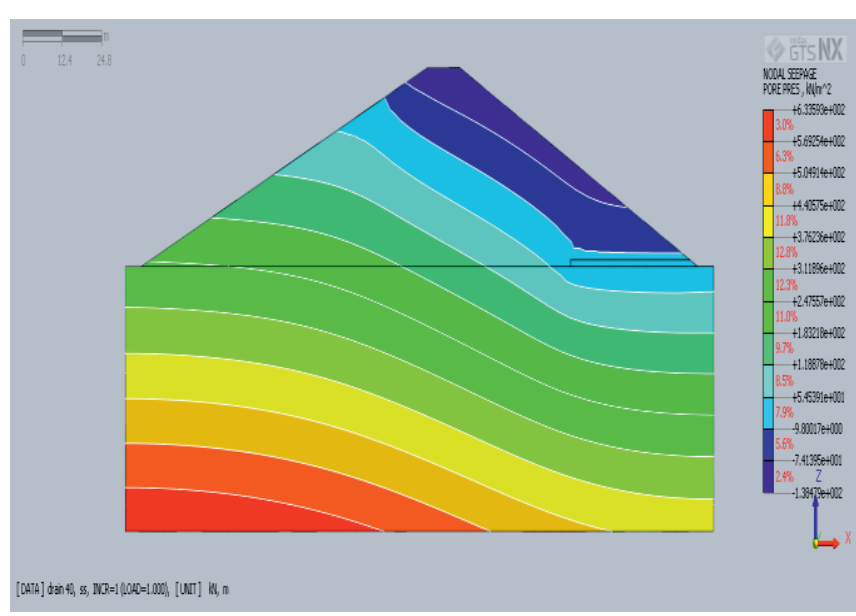

Figure 5. Pore water pressure variation of an earth dam with horizontal drain

\subsection{Effect of sheet pile length on pore water pressure}

Effect of sheet pile length at $\mathrm{B} / 8$ distance from downstream had been studied. Figure 4 depict that pore water pressure is increasing with the increase in length of sheet pile up to the location of sheet pile whereas at downstream side of sheet pile, the pore water pressures is decreasing with the increase in length of the sheet pile. $3 \mathrm{D}$ model with pore water pressure is depicted in Figure 7.
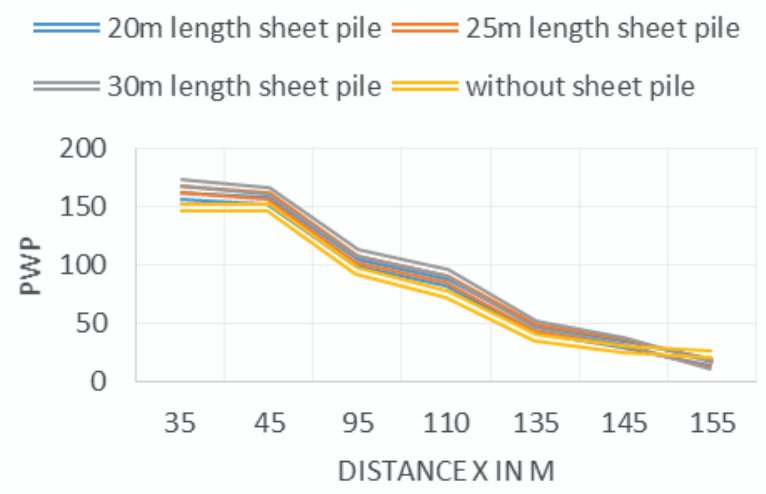

Figure 6. Variation of pore water pressure in an earthen dam for different lengths of sheet pile at a position $\mathrm{B} / 8$ distance from $\mathrm{d} / \mathrm{s}$

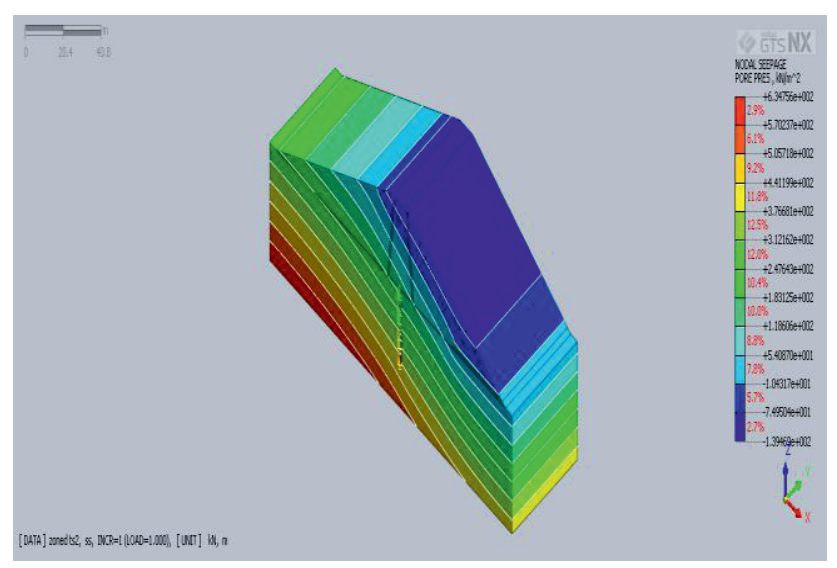

Figure 7. 3D pore water pressure variation of an earth dam with sheet pile

\subsection{Effect of sheet pile location on pore water pressure}

Now effect of sheet pile location for $30 \mathrm{~m}$ length of sheet pile as well as without sheet pile has been analyzed. The location of sheet pile shifts from downstream to upstream. It has been observed from Figures 8 and 9 that the pore water pressure increases at the upstream side of the dam. Pore water pressure reduces at the downstream side in comparison to upstream side due to ease of drainage.

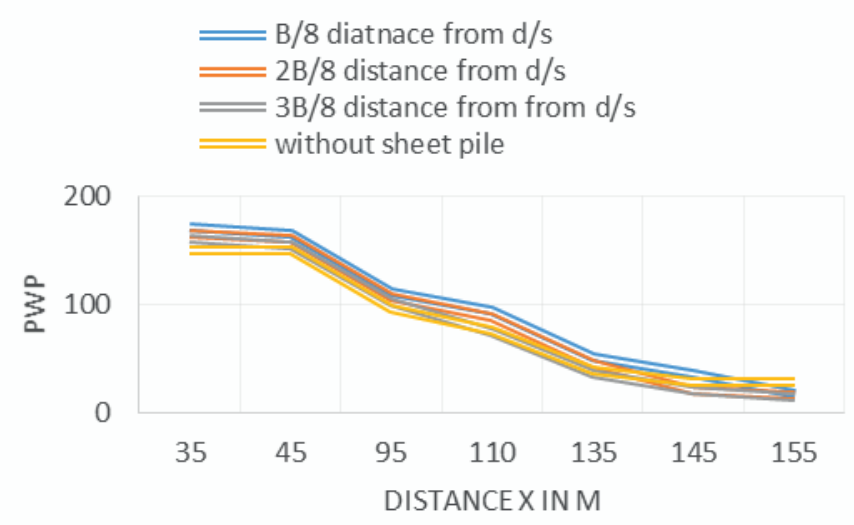

Figure 8. Variation of pore water pressure in earthen dam with different locations in $\mathrm{d} / \mathrm{s}$ with $30 \mathrm{~m}$ length sheet pile 


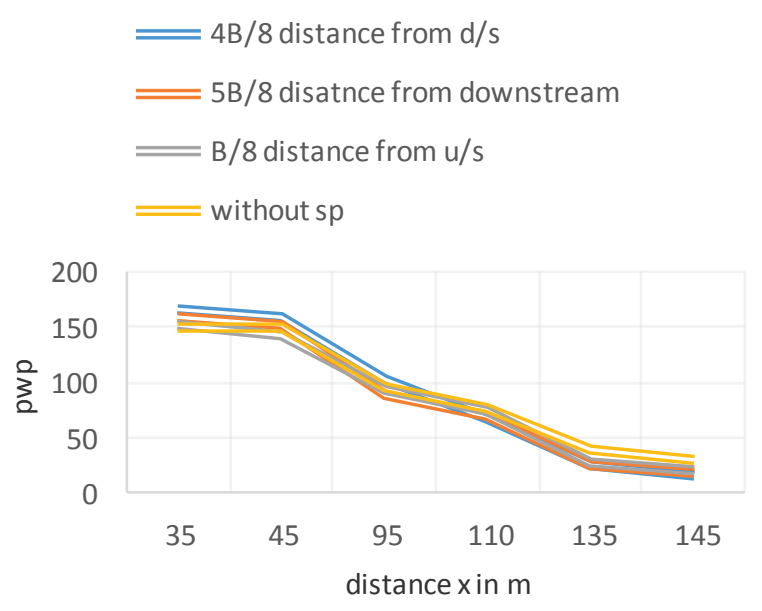

Figure 9. Variation of pore water pressure in earthen dam with different locations in $\mathrm{d} / \mathrm{s}$ with $30 \mathrm{~m}$ length sheet pile

\subsection{Effect of drawdown rate on pore water pressure}

Drawdown rate of $2 \mathrm{~m}$ /day up to 5 days has been considered for analysis. It has also been compare with the steady state seepage analysis as shown in Figure 10. On $5^{\text {th }}$ day the pore water pressure are higher compared to the steady state in a homogeneous earthen dam.

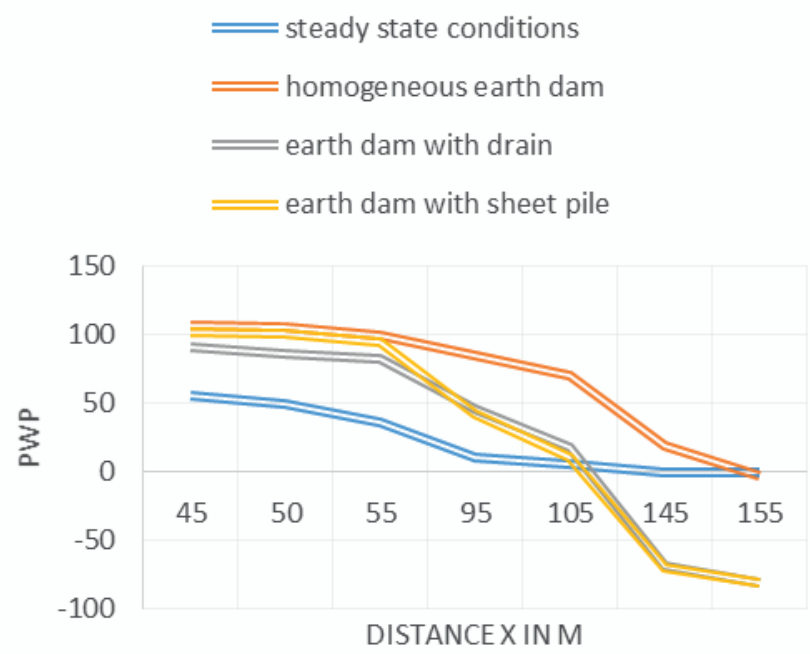

Figure 10. Variation of pore water pressure in an earthen dam under transient conditions (day 5)

The pore water pressure remains high at upstream side whereas pore water pressure gradually decreases at the downstream side. In comparison to sheet pile horizontal drain have relatively less pore water pressure at upstream side. The negative pore water pressure is predominant in the earthen dam with sheet pile and with drain. Though these are negligible in the case of homogeneous earthen dam.

\section{Conclusions}

The three dimensional analysis to determine the distribution of seepage characteristics in an earth dam is complex. Attempt has been made in this work to obtain these distributions by means of three dimensional finite element simulations. These simulations and output yields some conclusions which are summarized in the following section.

a) The pore water pressure during steady state and transient state had been decreased phenomenally at the upstream face due to the presence of horizontal drain at the downstream side.

b) The pore water pressure values decreased, as the location of sheet pile shifted towards upstream side of the dam.

c) The pore water pressure during drawdown conditions remained higher at the upstream side of the dam and also at the central core.

d) During drawdown conditions, an analysis should be done to decrease the pore water pressure the installation of horizontal blanket drains at upstream side of the dam.

\section{References}

1. L. Lam, D. G. Fredlund, and S. L. Barbour. "Transient seepage model for saturated-unsaturated soil systems: a geotechnical engineering approach". Can. Geotech. J. 24. 565-580 (1987)

2. C. W. W. Ng and Shi. "A numerical investigation of stability of unsaturated soil slopes subjected to transient seepage". Computer geotechnics, vol 22, No. 1, pp. 1-28,1998.

3. An-Nan Zhou, Daichao Sheng, Jie Li. “ Modelling water retention and volume changes behaviours of unsaturated soils in non-isothermal conditions. Computer and geotechnics 55(2014) 1-13

4. C.Yang, D. Sheng and J.P. Carter. "Hysteretic seepage analysis in unsaturated soil covers". Unsaturated soil theory and practice 2011, ISBN 978-616-7522-77-7.

5. Kenneth Gavin, Jianfeng Xue."A simple method to analsze infilteration into unsaturated soil slopes". Computer and geotechnics 35 (2008) 223-230.

6. Chao Yang, Daichao Sheng, John P. Carter. Effect of hydraulic hysteresis on seepage analysis for unsaturated soil". Computer and geotechnics 41 (2012) 36-56. 
